\title{
Immediate and Long-Term Effects of an 8-Week Digital Mental Health Intervention on Adults With Poorly Managed Type 2 Diabetes: Protocol for a Randomized Controlled Trial
}

Eliane Boucher ${ }^{1}$, PhD; Judith T Moskowitz ${ }^{2}$, MPH, PhD; Gina M Kackloudis ${ }^{1}$, MPH; Julia L Stafford ${ }^{1}$, BSc; Ian Kwok $^{2}$, MA; Acacia C Parks ${ }^{1}$, PhD

\author{
${ }^{1}$ Happify Health, New York, NY, United States \\ ${ }^{2}$ Feinberg School of Medicine, Northwestern University, Chicago, IL, United States
}

\section{Corresponding Author:}

Eliane Boucher, $\mathrm{PhD}$

Happify Health

51 East 12th Street, 5th Floor

New York, NY, 10003

United States

Phone: 14322585233

Email: eliane@happify.com

\begin{abstract}
Background: Diabetes is a leading cause of years of life lost and accounts for approximately one-fourth of health care dollars spent in the United States. Many of these costs are related to poor medication adherence and lack of self-care behaviors and are thus preventable. Depression, which is more prevalent among people with diabetes than in the general population, predicts poorer management of one's diabetes, whereas positive affect predicts engaging in more positive health behaviors. Consequently, interventions that improve depression and positive affect may also improve diabetes-related outcomes among people with diabetes. Although preliminary research on the impact of such interventions among people with diabetes is promising, these studies focused primarily on in-person interventions, have had small samples, and lack long-term follow-up.
\end{abstract}

Objective: This study aims to examine the short- and long-term effects of a digital therapeutic platform focused on mental health among adults with poorly managed type 2 diabetes and elevated levels of depression.

Methods: This is a randomized controlled trial in which adults with a type 2 diabetes diagnosis, elevated hemoglobin $\mathrm{A}_{1 \mathrm{c}}$ $\left(\mathrm{HbA}_{1 \mathrm{c}}\right.$ ) levels $(\geqq 7)$, and moderate to severe depressive symptoms will be randomly assigned to a positive emotion regulation skills intervention group or a sham digital intervention with only psychoeducational content. The study will take place over 14 months, including the 8-week intervention (or control) delivered via a digital therapeutic platform (Happify Health) and follow-up assessments at 3, 6, and 12 months postintervention. Throughout the intervention and for 1 week at each postintervention follow-up, participants will complete daily assessments of diabetes-related distress, diabetes regimen adherence, and mood. Our primary outcome, $\mathrm{HbA}_{1 \mathrm{c}}$, will be self-reported every 3 months throughout the study. Secondary and exploratory outcomes will be assessed at baseline; at 8 weeks; and at 3, 6, and 12 months postintervention.

Results: Recruitment is expected to begin in June 2020. Participants will begin the study as they are recruited and will finish in waves. The final wave of data collection from the 8-week intervention is expected for winter 2020, with the completion of the 12-month follow-up in winter 2021.

Conclusions: Although previous research suggests that in-person psychological interventions have promising effects on both psychological and physical outcomes among adults with diabetes, digital interventions can be advantageous because they are easily scalable and reduce many barriers that prevent people from seeking treatment. This trial will provide important information about the effects of a digital mental health intervention among adults with type 2 diabetes, assessing both short- and long-term effects of this intervention on $\mathrm{HbAlc}$, depressive symptoms, and other diabetes-specific outcomes. If successful, this may introduce a scalable intervention that would help reduce some of the preventable costs associated with diabetes.

Trial Registration: ClinicalTrials.gov NCT04068805; https://clinicaltrials.gov/ct2/show/NCT04068805.

International Registered Report Identifier (IRRID): PRR1-10.2196/18578 
(JMIR Res Protoc 2020;9(8):e18578) doi: 10.2196/18578

\section{KEYWORDS}

online intervention; diabetes mellitus; type 2; mental health; randomized clinical trial; positive psychology; HbA1c

\section{Introduction}

\section{Prevalence and Costs of Diabetes}

Diabetes is one of the most common chronic health conditions worldwide [1] and is considered to be a leading cause of years of life lost [2]. The prevalence of diabetes has also been increasing since the mid-1980s [3]. According to the Centers for Disease Control and Prevention, approximately $9.5 \%$ of the American population had diabetes in 2015 [4], most of which were type 2 diabetes diagnoses [4], and approximately $34 \%$ of the population met the criteria for prediabetes, suggesting that even more people are at risk of developing type 2 diabetes [4]. By $2030,4.4 \%$ of the global population is estimated to have diabetes [5].

The economic cost associated with diabetes is also increasing because of the increased prevalence and the increased cost per patient [6]. The American Diabetes Association recently estimated the total annual cost of diabetes at US \$327 billion when considering both medical costs and reduced productivity [7], and people with diabetes account for $25 \%$ of all health care dollars spent in the United States [7]. On an individual level, people with a diabetes diagnosis spend approximately US $\$ 16,750$ annually for medical expenses, and more than $57 \%$ of those expenses are directly related to their diabetes [7]. The projected global costs associated with diabetes are estimated to increase from US \$1.32 trillion in 2015 to US \$2.12 trillion by $2030[8]$.

However, many of these costs are preventable, resulting from poor diabetes management. In 2014, 577,040 diabetes-related hospitalizations in the United States were preventable [9], accounting for US $\$ 5.9$ billion of the diabetes-related health care costs [10]. Previous research shows that many people with diabetes struggle with medication compliance [11], which puts them at an increased risk for hospitalization and mortality [12]. Similarly, adherence to physician-recommended self-monitoring of blood glucose levels tends to be low, particularly among people with type 2 diabetes [13].

\section{Diabetes and Mental Health}

People living with a chronic illness often report that depression is a major barrier to managing their condition and, worse, often do not seek treatment for their depression due to perceived stigma [14]. This is particularly relevant for people with diabetes, who are at a higher risk for depression than the general population [15]. Although depression does not appear to be directly related to hemoglobin $\mathrm{A}_{1 \mathrm{c}}\left(\mathrm{HbA}_{1 \mathrm{c}}\right)$, a measure of average blood sugar levels over 3 months, in patients with diabetes [16,17], comorbid depression predicts poorer diet, poorer medication compliance, and greater functional impairment [18], which, in turn, predicts higher rates of diabetes-related preventable hospitalizations [19] and health care costs [18]. In addition, depression predicts higher levels of diabetes-related distress [20]. In turn, diabetes-related distress predicts poorer $\mathrm{HbA}_{1 \mathrm{c}}$ [16], and reducing diabetes-related distress leads to significant improvements in $\mathrm{HbA}_{1 \mathrm{c}}$ level [17].

Conversely, higher levels of positive affect are associated with reduced mortality risk [21] and depression [22,23] among people with diabetes. Positive affect also promotes various health behaviors central to managing diabetes, including higher levels of physical exercise [24] and better diet [25]. Similarly, higher levels of self-compassion predict better behavioral and psychological outcomes among people with diabetes as well as better $\mathrm{HbA}_{1 \mathrm{c}}$ levels [26]. Conceivably, self-compassion may lead to improved diabetes outcomes because it promotes greater well-being and better mental health [27]; however, self-compassion may also lead to more adaptive responses to difficulties patients face with managing their condition and, in turn, promote better diabetes management, including more effective health care use, healthy diet and physical activity, and better management of blood glucose levels [26].

Taken together, these findings suggest that better mental health among people with diabetes is associated with less diabetes-related distress and healthier lifestyles, which, in turn, predict better diabetes-related outcomes. Consequently, psychological interventions targeting mental health may lead people with diabetes to engage in healthier lifestyles, indirectly improving diabetes-related outcomes and reducing associated costs [22,28].

\section{Impact of Mental Health Interventions on Diabetes}

Research on the impact of mental health interventions applied specifically to people living with diabetes remains limited. Mindfulness and positive psychology (PP) interventions, which are effective in reducing depression and increasing well-being in the general population [29], have shown promise in improving depression, diabetes-related distress, and $\mathrm{HbA}_{1 \mathrm{c}}$ levels among people with type 1 or 2 diabetes [30]. A recent systematic review showed that such interventions, particularly mindfulness-based interventions, led to improvements in psychological outcomes, including self-efficacy, self-compassion, well-being, mental health-related quality of life, positive affect, stress, diabetes-related distress, depression, and anxiety [30]. Mindfulness-based interventions also appeared to lead to improvements in $\mathrm{HbA}_{1 \mathrm{c}}$ levels, although in some cases, the effects were not observed until 1 or 3 months postintervention [30]. Other research also suggested that mindfulness-based interventions have small to moderate effects on metabolic control [31].

Such interventions appear to be particularly successful when patients have higher baseline levels of diabetes-related distress and when interventions are delivered in a group format, draw on mindfulness-based stress reduction (MBSR), and include home practice assignments [32]. Although few of these studies have included long-term follow-up, there is preliminary evidence that the effects of mindfulness-based interventions on depressive 
symptoms are maintained, or even stronger, after 6 months $[30,32]$, although they may dissipate after 2 or 3 years postintervention [30]. Some findings also suggest that the effects of mindfulness-based interventions on $\mathrm{HbA}_{1 \mathrm{c}}$ levels may actually be stronger 1 or 3 months postintervention rather than immediately postintervention [30].

Preliminary research also suggests that cognitive behavioral therapy (CBT) may be effective in treating depression among individuals with diabetes, although the effects on diabetes-specific outcomes are mixed, and may be limited to people with high baseline depression scores [33]. In one study of adults with uncontrolled diabetes and unipolar depression, CBT designed for adherence and depression led to improvements in medication adherence and self-monitoring of blood glucose, $\mathrm{HbA}_{1 \mathrm{c}}$, and depression, and these improvements were maintained for up to 12 months [34]. However, in another study, CBT was associated with improved depression relative to a control group, but the levels of glycosylated hemoglobin were better in the CBT group than in the control group only at 6 months posttreatment [35]. Similarly, a recent systematic review of 10 randomized controlled trials (RCTs) showed that CBT improved depression, quality of life, fasting glucose, and anxiety but not glycemic control or diabetes-related distress [36].

\section{Digital Interventions}

Although this research is promising, most of these studies have focused on the impact of in-person interventions. However, there are numerous barriers to in-person treatment that prevent people from seeking treatment [37], including stigma [38] and a shortage of mental health professionals [39]. Internet-based interventions offer a cost-effective means of providing access to large populations [40], while also reducing some of the other barriers to seeking treatment by increasing convenience [41] and anonymity [42]. Indeed, research suggests that people with comorbid depression and diabetes find web-based interventions attractive and may reach a population that would not otherwise seek treatment [43].

Although previous research supports the effectiveness of internet-based interventions in physical health [44] and mental health [45] domains, few studies have tested the impact of internet-based interventions among people with diabetes specifically, and what research has been done on the benefits of mobile health interventions among people with diabetes yielded mixed results [46]. Most studies on the effects of web-based interventions on people with diabetes found no significant effects on depression or distress [47,48], whereas research demonstrating effects on depressive symptoms found no effects on diabetes-specific outcomes [22]. However, unlike most studies of in-person CBT, these studies did not include a sample of patients with diabetes and elevated levels of depression. One study of individuals with a diabetes diagnosis and elevated depressive symptoms found that internet-based CBT reduced depression, although they found no benefits for glycemic control [49]. Therefore, additional research testing the effectiveness of digital mental health interventions specifically among people with diabetes and elevated depressive

symptoms is necessary, particularly studies with long-term follow-up and larger sample sizes [47].

\section{Objectives of This Study}

This study aims to examine the effectiveness of a digital therapeutics platform named Happify Health on people with poorly managed type 2 diabetes and elevated depressive symptoms. Happify Health is a digital intervention platform focused on mental health and its impact on other diseases that can be accessed via the internet or mobile app. Unlike most other interventions tested in person or digitally, which draw on just one theoretical approach, Happify Health activities draw from each of the three major theoretical approaches: CBT [50], MBSR [51], and PP [52-54]. Therefore, Happify Health uses multiple pathways to improve users' mental health by incorporating strengths from all three theoretical approaches, while simultaneously improving person-activity fit relative to other singular approaches by offering users more opportunities to find types of activities that suit them.

Activities within Happify Health were developed by identifying evidence-based tasks and interventions that were shown to be effective in at least two separate studies and in different samples [55]. These activities fall into different themes: savor (building mindfulness skills), thank (gratitude), aspire (optimism, goal setting, and finding meaning and purpose), give (kindness, forgiveness, and prosociality), empathize (self-compassion and perspective taking), and revive (physical health). Activities from these different themes are then organized into tracks, developed to help users improve in a specific area of concern such as reducing stress. Within each track, users can select specific activities and may also switch tracks before completing them or access activities in a free play format. Consequently, users have the ability to choose tracks and activities that better fit them, which has been shown to improve outcomes [56].

Observational studies of Happify Health users demonstrate that usage over 8 weeks is associated with more than a $27 \%$ increase in positive emotions, and high-use participants see even greater improvement [57,58]. A later RCT also demonstrated that Happify Health users who completed at least two activities per week reported significantly more improvement in depression, anxiety, and resilience than those who completed fewer activities or participants assigned to the control group [59]. Similar effects were obtained from RCTs focused specifically on people with higher levels of emotional or workplace distress [60]. More recent research also suggests that Happify Health use improves subjective well-being among people living with chronic physical conditions, including, but not limited to, diabetes, at the same rate as those without chronic conditions [61]. Consequently, there is preliminary evidence to suggest that Happify Health could effectively improve subjective and psychological well-being among individuals diagnosed with type 2 diabetes. However, no research has examined whether Happify Health use could also positively improve outcomes associated with their diabetes, including how well they manage their condition, their level of diabetes-related distress, and physical outcomes such as $\mathrm{HbA}_{1 \mathrm{c}}$ levels.

Therefore, in this study, our goal is to examine whether Happify Health use over the course of 8 weeks also helps to improve 
diabetes-specific outcomes. To do so, we plan to compare changes in $\mathrm{HbA}_{1 \mathrm{c}}$ levels among adults with poorly managed type 2 diabetes and elevated depressive symptoms who have completed 8 weeks of activities on Happify Health or 8 weeks of a sham digital intervention. Secondary outcomes include depression, positive affect, and other diabetes-specific outcomes such as medication adherence, diabetes-related distress, and diabetes-related self-care activities. In addition, although many other studies (particularly mindfulness and PP interventions) did not examine long-term effects, we plan to explore the long-term effects of Happify Health use on both primary and secondary outcomes at 3, 6, and 12 months postintervention.

\section{Methods}

\section{Recruitment Strategy}

We plan to recruit participants by capitalizing on the existing process used to draw new users to Happify Health, including advertisements on Facebook and other social media sources. To attract individuals with type 2 diabetes specifically, targeted advertisements will also be posted on websites that connect potential participants with research studies and clinical trials (eg, Research Match) and on websites relevant to people living with type 2 diabetes.

Interested participants will be directed to a web-based survey to determine eligibility. The survey questions will include questions on age, location, previous Happify Health usage, diagnosed chronic illnesses, self-reported $\mathrm{HbA}_{1 \mathrm{c}}$ level, the Patient Health Questionnaire (PHQ) [62], and contact information. Users who meet initial inclusion criteria will then be contacted directly by Happify Health research staff to discuss the study in more detail. During this call, all eligibility questions will be readministered to ensure that the potential participant still meets the inclusion criteria. Those who agree to participate after this call will be sent an email to begin a week-long run-in period; during this run-in period, participants will be instructed to answer a brief web-based survey including three questions assessing daily diabetes-related distress, diabetes regimen adherence, and mood. Participants who complete this run-in period will then be sent an email instructing them to download the Happify Health app and to begin the study.

\section{Inclusion and Exclusion Criteria}

Participants will qualify for the study if they are aged 18 years or older, currently living in the United States, have never used Happify Health before, and have a current diagnosis of type 2 diabetes. In addition, as we are targeting participants with poorly managed diabetes and recent recommendations are that below $7 \%$ is a reasonable glycemic goal for most adults with type 2 diabetes [63], participants will be included if their most recent $\mathrm{HbA}_{1 \mathrm{c}}$ level is at least 7\%. Similarly, as we are also targeting participants with elevated depressive symptoms, participants will be included if their scores on the PHQ are at least 15, which is indicative of moderately severe depression [62]. Participants will also need to indicate their willingness to provide $\mathrm{HbA}_{1 \mathrm{c}}$ results throughout the study, complete daily assessments, and engage with the platform to qualify for the study. Finally, participants will also have to complete 5 of the 7 daily questionnaires during an initial qualifying period (refer to the Procedures section for more detail) to participate in the study.

\section{Participants}

This study is an RCT (NCT04068805) with an initial target sample size of 400 participants (200 participants per condition). Recruitment will continue until 400 participants have successfully completed pretesting and have been randomized to condition.

Although previous RCTs using Happify Health had response rates ranging from $56 \%$ to $72 \%$ for an 8 -week posttest [60], as the first attempt to include long-term follow-up of Happify Health users, the level of attrition beyond the 8-week intervention is difficult to estimate. The few previous tests of mental health interventions on people with diabetes that included long-term follow-up reported relatively low attrition for 6-month [35,64] and 12-month [34,65] follow-ups; however, all these studies involved in-person interventions and often included booster sessions, thereby increasing the level of contact with participants and increasing response rates. The levels of attrition are much higher in research using digital interventions [66], although dropout rates are lower in RCTs than in open-access interventions [67]. Consequently, although we predict attrition for long-term follow-ups to be higher in this study than in previous research with in-person interventions, it is unclear what percentage of participants to expect for our 3-, 6-, and 12-month assessments.

\section{Participant Compensation}

Participants will receive three types of compensation throughout the study. After the baseline assessment (for which participants will not be compensated), participants will be compensated with Amazon gift cards valued at US \$15 for completing each assessment. As separate compensation for completing daily assessments (as part of the 8-week intervention and during the 3-, 6-, and 12-month follow-ups), participants will earn US \$1 for each daily assessment, for a possible total of US \$56 for completing daily assessments during the intervention and US \$28 for completing the week-long daily assessments at postintervention and during the 3-, 6-, and 12-month follow-ups. Finally, participants will be compensated with US $\$ 5$ for obtaining and reporting each $\mathrm{HbA}_{1 \mathrm{c}}$ recording after baseline. Thus, participants will be compensated with a total of US \$164 if they complete all assessments at all waves of data collection.

\section{Outcome Measures}

All assessments will be administered via Happify Health, and participants who do not complete measures will be sent email reminders; however, participants may withdraw from the study or skip assessments at any time. To link participant data across assessments and other data collections, each participant will be assigned a unique study ID number; participants will otherwise remain anonymous throughout the study. In addition to the primary and secondary outcome measures described in the following sections, other exploratory measures will also be included that are not reported here. 


\section{Primary Outcome: Hemoglobin $A_{1 c}$}

Participants will self-report their $\mathrm{HbA}_{1 \mathrm{c}}$ levels, a measure of the average blood glucose levels over the past 3 months, 5 times throughout the study: at baseline, week 12 (3 weeks postintervention), week 24 (3 weeks after the 3-month postintervention assessment), week 36 (3 weeks after the 6-month postintervention assessment), and week 57 (at the 12-month postintervention assessment). At each assessment, participants will also report the date when they received this $\mathrm{HbA}_{1 \mathrm{c}}$ reading to verify that it falls in the correct time frame.

\section{Secondary Outcomes}

\section{Diabetes Distress Scale}

Diabetes distress scale [68] is a 17-item scale that assesses the extent to which certain diabetes-related situations have been a problem for participants. Each item represents a potential problem area for individuals living with diabetes (eg, feeling that I am often failing with my diabetes routine), and participants indicate the extent to which they have been distressed or bothered by that issue during the past month on a scale ranging from 1 (not a problem) to 6 (a very serious problem). The responses are averaged so that scores can range from 1 to 6 , where higher scores indicate higher levels of distress, and scores of 3 or greater are considered to be clinically significant levels of diabetes-related distress.

\section{Measures of Medication Adherence Scale}

Measures of Medication Adherence Scale [69] is a 4-item self-report measure of medication adherence and thus will only be shown to participants who indicate they are currently prescribed medication for diabetes on a preceding question. This scale will be modified slightly to ask participants specifically about adherence to diabetes medication over the past week. For each item (eg, Over the past week, did you ever forget to take your diabetes medicine?), participants indicate yes or no. All yes responses are coded as 0 , and no responses are coded as 1 . The responses are then summed so that higher scores indicate greater medication nonadherence.

\section{Summary of Diabetes Self-Care Activities}

Summary of diabetes self-care activities [70] is an 11-item measure of self-reported adherence to diabetes self-care activities. For 10 items, participants indicate on how many days they engaged in self-care activities related to diet (eg, How many of the last 7 days have you followed a healthful eating plan?), exercise (eg, On how many of the last 7 days did you participate in at least 30 min of physical activity?), blood sugar testing (eg, On how many of the last 7 days did you test your blood sugar?), and foot care (eg, On how many of the last 7 days did you check your feet?) over the past week on a scale ranging from 0 to 7 . One item also asks participants to indicate the frequency of smoking over the past week (ie, Have you smoked a cigarette, even 1 puff, during the past 7 days?) on a scale ranging from 0 (no) to 1 (yes); participants who respond yes are then asked to indicate how many cigarettes they smoked on an average day. Separate scores are then created for each subscale.

\section{Patient Health Questionnaire}

PHQ-9 [62] is a 9-item scale measuring depressive symptomology. Each item represents a depressive symptom (eg, feeling down, depressed, or hopeless), and participants indicate how often they have been bothered by each symptom over the past 2 weeks on a scale ranging from 0 (not at all) to 3 (nearly every day). The responses are then summed such that scores can range from 0 to 27 , and higher scores indicate more severe depressive symptoms.

\section{Patient-Reported Outcomes Measurement Information Systems: Positive Affect Subscale}

Participants will also complete the positive affect subscale of the Patient-Reported Outcomes Measurement Information Systems [71] scale. This subscale asks participants to indicate how much they felt each of the 15 emotions (eg, "I felt cheerful") over the past 7 days on a scale ranging from 1 (not at all) to 5 (very much). Items are summed so that higher scores indicate greater positive affect.

\section{Daily Assessments}

\section{Diabetes-Related Distress}

We will assess daily levels of diabetes-related distress with a single item (ie, How would you rate your diabetes-related distress, on average, over the past 24 hours?) rated on a scale ranging from 1 (very low) to 7 (very high).

\section{Diabetes Regimen Adherence}

We will assess participants' daily regimen adherence using a single item (ie, Which of the following activities in your diabetes regimen did you complete over the past 24 hours?) where participants check any of the following options that apply to their situation: monitored blood sugar, ate according to healthy eating diet, engaged in physical activity, took diabetes medication as prescribed, or did not follow my diabetes regimen at all.

\section{Daily Mood}

We will assess participants' daily mood with a single item (ie, "How depressed did you feel, on average, over the past 24 hours?") rated on a scale ranging from 1 (not at all) to 7 (extremely) [72].

\section{Procedures}

Participation in this study will take place over approximately 14 months, including an 8-week intervention (or corresponding control) delivered via Happify Health as well as follow-up assessments at 3, 6, and 12 months postintervention. To ensure that $\mathrm{HbA}_{1 \mathrm{c}}$ levels reported postintervention reflect average glucose levels only after starting the intervention, all participants will begin the study within 3 weeks of obtaining their most recent $\mathrm{HbA}_{1 \mathrm{c}}$ levels. Participants who indicate that their most recent $\mathrm{HbA}_{1 \mathrm{c}}$ levels were obtained before that when contacted by phone will wait to begin the study until they obtain their following $\mathrm{HbA}_{1 \mathrm{c}}$ measurement and researchers confirm that they meet the inclusion criterion.

Once participants are ready to begin the study, they will be directed to complete 1 week of daily assessments without 
exposure to either condition. Participants who complete fewer than 5 of these assessments will be disqualified from the study. Those who complete at least five of the daily assessments during this qualifying period will be directed to download the mobile app and complete the regular onboarding questionnaire for Happify Health; participants will be randomly assigned to either the positive emotion regulation skills intervention group or the control group upon completing these questions. Following randomization, participants will be prompted to complete the baseline assessment.

Participants will then be instructed to begin using their assigned version of Happify Health. Although participants will not be given explicit instructions on how often they should use the platform, they will be encouraged to engage with the platform daily. Participants will receive daily push notifications on their mobile device to remind them to access the platform and answer daily questionnaires, and they will also receive weekly emails as part of the Happify Health platform to help keep them engaged with the program. In addition, to improve use rates and participant retention, research staff will call participants to inquire about problems when a participant has not engaged with the Happify Health platform at all for 1 week.

After 8 weeks, participants will be instructed to complete the postintervention assessment; this assessment will be identical to the baseline with the exception of $\mathrm{HbA}_{1 \mathrm{c}}$ assessment, which will occur 3 weeks later via the Happify Health app. After completing this assessment, participants will receive an email instructing them to answer daily questions for 1 week and to remind them that we will contact them again in 3, 6, and 12 months for follow-up assessments and that they should continue to use their assigned version of Happify Health as they see fit. Participants will then receive emails instructing them to complete each of the 3-, 6-, and 12-month assessments, which will also be accompanied by 1 week of daily assessments at each follow-up period. Table 1 provides the schedule of activities. To improve participant retention, participants who do not complete the postintervention, 3-, 6-, and 12-month assessments will also receive a reminder phone call from the research staff.

Table 1. Schedule of activities for prescreen, intervention period, and follow-up assessments.

\begin{tabular}{|c|c|c|c|c|c|c|c|c|c|c|c|}
\hline \multirow[t]{2}{*}{ Assessments } & \multicolumn{11}{|l|}{ Time } \\
\hline & Prescreen & $\begin{array}{l}\text { Week 1: } \\
\text { qualifying } \\
\text { period }\end{array}$ & $\begin{array}{l}\text { Week 2: } \\
\text { baseline and } \\
\text { first week of } \\
\text { intervention }\end{array}$ & $\begin{array}{l}\text { Weeks 3-9: in- } \\
\text { tervention }\end{array}$ & $\begin{array}{l}\text { Week } \\
10\end{array}$ & $\begin{array}{l}\text { Week } \\
12\end{array}$ & $\begin{array}{l}\text { Week } \\
21: 3- \\
\text { month } \\
\text { follow- } \\
\text { up }\end{array}$ & $\begin{array}{l}\text { Week } \\
24\end{array}$ & $\begin{array}{l}\text { Week 33: } \\
\text { 6-month } \\
\text { follow-up }\end{array}$ & $\begin{array}{l}\text { Week } \\
36\end{array}$ & $\begin{array}{l}\text { Week } \\
57: 12- \\
\text { month } \\
\text { follow- } \\
\text { up }\end{array}$ \\
\hline \multicolumn{12}{|l|}{ Primary outcome } \\
\hline $\mathrm{HbA}_{1 \mathrm{c}}{ }^{\mathrm{a}}$ & $X^{b}$ & $\mathrm{~N} / \mathrm{A}^{\mathrm{c}}$ & $X$ & N/A & NA/ & $X$ & N/A & $X$ & N/A & $X$ & $X$ \\
\hline \multicolumn{12}{|l|}{ Secondary outcomes } \\
\hline $\begin{array}{l}\text { Diabetes dis- } \\
\text { tress scale }\end{array}$ & N/A & N/A & $X$ & N/A & $X$ & N/A & $X$ & N/A & $X$ & N/A & $X$ \\
\hline $\begin{array}{l}\text { Measures of } \\
\text { Medication Ad- } \\
\text { herence Scale }\end{array}$ & N/A & N/A & $X$ & N/A & $X$ & N/A & $\mathrm{X}$ & N/A & $X$ & N/A & $\mathrm{X}$ \\
\hline $\begin{array}{l}\text { Summary of dia- } \\
\text { betes self-care } \\
\text { activities }\end{array}$ & N/A & N/A & $\mathrm{X}$ & N/A & $\mathrm{X}$ & N/A & $\mathrm{X}$ & N/A & $\mathrm{X}$ & N/A & $\mathrm{X}$ \\
\hline $\begin{array}{l}\text { Patient Health } \\
\text { Questionnaire }\end{array}$ & $\mathrm{X}$ & N/A & $\mathrm{X}$ & N/A & $X$ & N/A & $\mathrm{X}$ & N/A & $\mathrm{X}$ & N/A & $\mathrm{X}$ \\
\hline $\begin{array}{l}\text { Positive affect } \\
\text { subscale }\end{array}$ & N/A & N/A & $X$ & N/A & $X$ & N/A & $X$ & N/A & $X$ & N/A & $X$ \\
\hline $\begin{array}{l}\text { Daily assess- } \\
\text { ments }\end{array}$ & N/A & $X$ & $X$ & $X$ & $X$ & N/A & $X$ & N/A & $X$ & N/A & $X$ \\
\hline
\end{tabular}

${ }^{\mathrm{a}} \mathrm{HbA}_{1 \mathrm{C}}$ : hemoglobin $\mathrm{A}_{1 \mathrm{c}}$.

${ }^{\mathrm{b}} \mathrm{X}$ : assessment administered.

${ }^{\mathrm{c}} \mathrm{N} / \mathrm{A}$ : not applicable.

\section{Intervention Group}

Participants assigned to the positive emotion regulation skills intervention will receive full access to the Happify Health platform. However, their version will feature a diabetes-related track focusing on building skills for greater happiness, reducing stress, and coping better with diabetes (Figure 1). Although the description of the track cues them to think about the impact of negative emotions on their diabetes and the benefits of increasing positive emotions, activities within the track are not focused specifically on diabetes. Importantly, although participants will be encouraged to use this particular track, they will not be required to start or complete the diabetes-related 
track and will be able to choose from all the other tracks available on Happify Health.

Figure 1. Screenshot of the featured track description for Developing Affective HeaLth to Improve Adherence intervention.
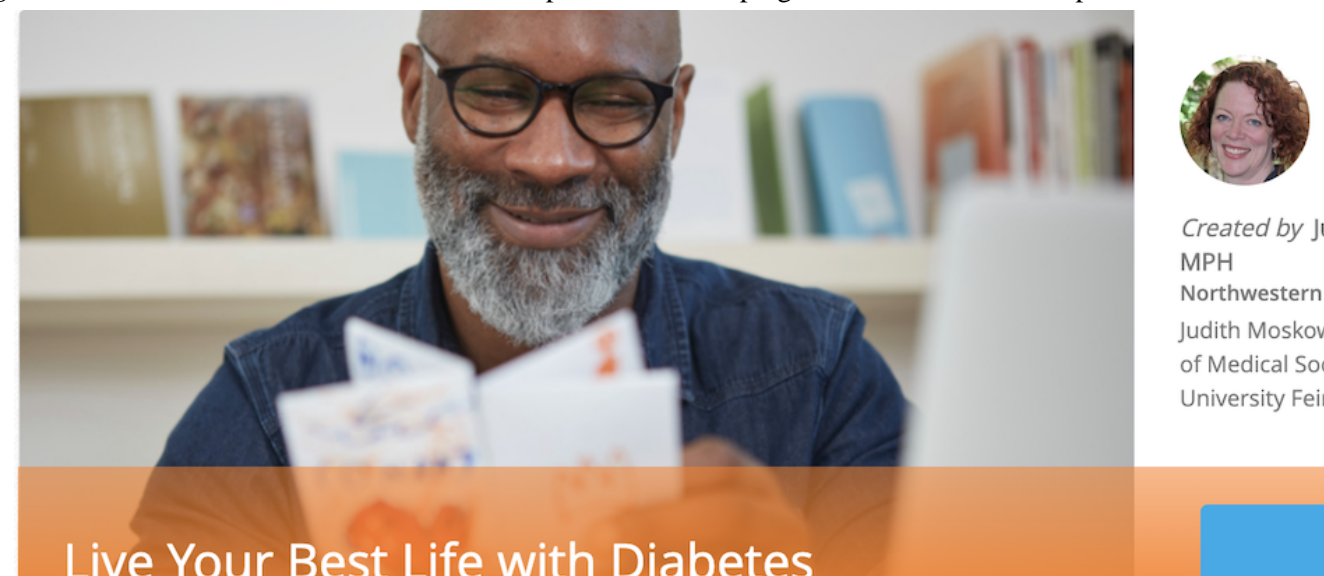

Share

Created by Judith T. Moskowitz, PhD,

$\mathrm{MPH}$

Northwestern University

Judith Moskowitz, PhD, MPH, is a Professor

of Medical Social Sciences at Northwestern

University Feinberg School of... Read full bio

Live Your Best Life with Diabetes

START TRACK

Preview

This track can help you:

- Build skills for greater happiness

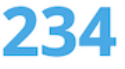

Reduce stress

- Cope better with your condition

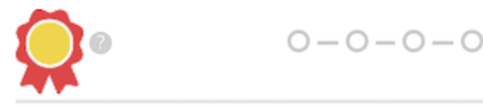

Evidence-based modalities in this track: ?

Joined

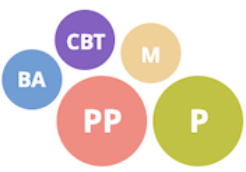

The featured diabetes-related track was designed by Happify Health and the second author, who is an expert on emotion and diabetes. The track is based on activities and content from the Developing Affective Health to Improve Adherence intervention originally developed by Moskowitz et al [21]. The version included in this study has four parts.

\section{Part 1}

This part contains 8 different activities and exercises focusing on savoring. For example, in 1 activity, Today' $s$ grateful moment, participants are asked to spend a few moments writing about something they are grateful for. In another activity, Let the good times roll, participants make a plan to spend time doing simple things that promote positive affect and then write about how it went after completing the tasks they planned.

\section{Part 2}

This part contains 9 different activities and exercises focusing on reframing negative thoughts. For example, in A week's worth of thanks, participants keep a gratitude journal about someone they are close to and spend time writing about why they are grateful for that person. In another activity, Savor the small stuff, participants spend a week doing something mindfully (eg, eating a meal or taking medication) and then write about how it went.

\section{Part 3}

This part contains 11 different activities that build on parts 1 and 2 but includes exercises promoting goal orientation and optimistic thinking. For example, in Give Myself a Break, where participants practice self-compassion and then spend time writing about how it went. In another activity, Loving-Kindness Meditation, participants verbalize good wishes when interacting with other people and then write about how it went.

\section{Part 4}

This part contains 11 different activities that promote resilience and helping others. For example, in What am I proud of?, participants spend some time thinking about something they are proud of and then write about it. In another activity, Help Someone, participants spend some time helping another person and then write about it.

Participants must complete one part before they can begin the following part, and they do so by earning either a silver medal (earned by completing all but 4 activities) or a gold medal (earned by completing all but 3 activities). Thus, participants will take varying lengths of time to complete a track, depending on their level of engagement with the platform. As participants will have access to the full Happify Health platform, if they complete the intervention track before the 8-week study period has elapsed or choose to change tracks before finishing, they will have access to all other available Happify Health tracks and instant-play activities (where they can choose to complete certain activities outside of dedicated tracks).

\section{Sham Digital Intervention}

Participants assigned to the control condition (Figure 2) will have access to a version of Happify Health that includes only polls on various mental health topics. After each poll, participants in this condition are provided with social comparison data about how their responses to the poll compared 
with other users' responses and information about why this topic is important (including references to relevant scientific studies). For example, after responding to a poll question that asks participants to indicate how often they have a deep or meaningful conversation with someone, participants will view psychoeducational information about the benefits of

Figure 2. Screenshot of the track description in sham digital intervention. conversation, including that people who spend less time alone and more time talking to others tend to be happier [73] and that the happiest people have much less small talk, but many more meaningful conversations compared with the least happy people [74].

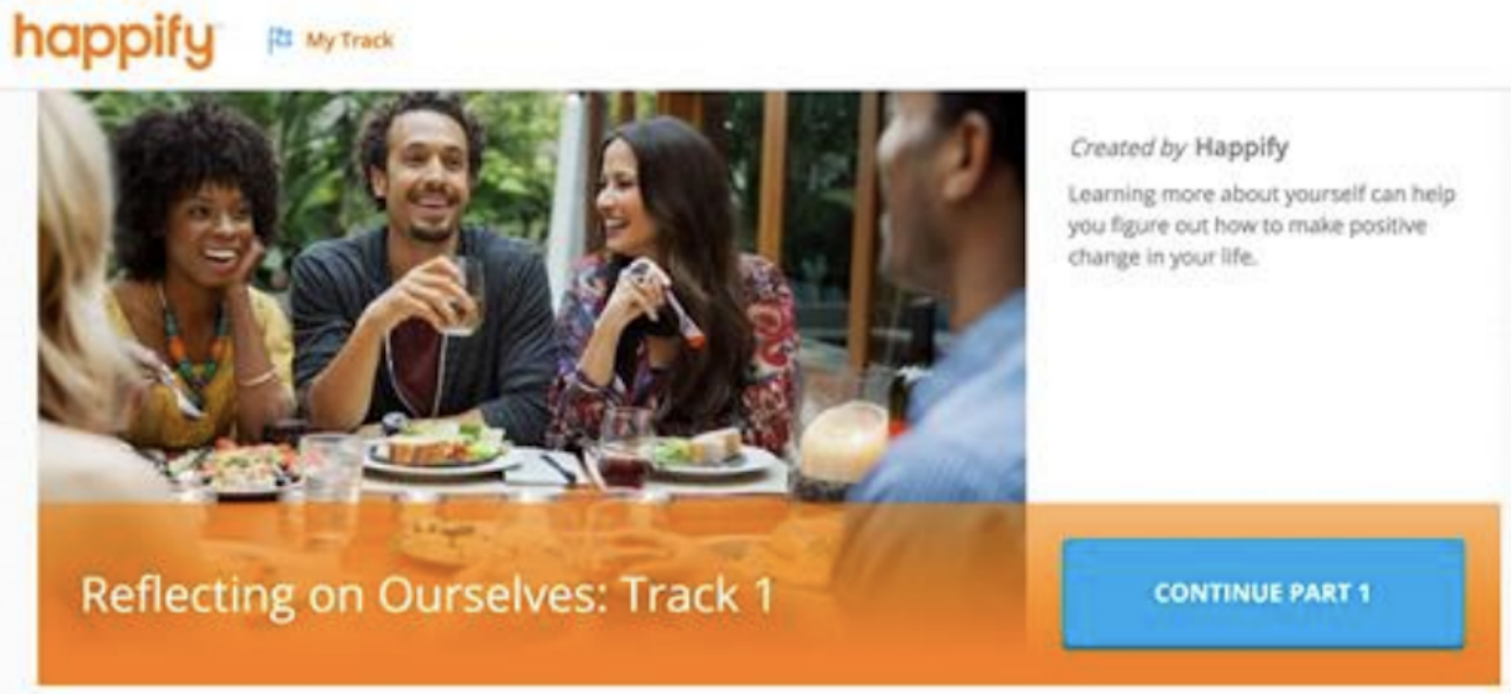

\section{This track can help you: \\ - Increase self-awareness \\ - Answer thought-provoking questions about yourself \\ - Find out where you stand compared to other people Rike you}

\section{Analysis Plan}

We plan to analyze the changes in primary and secondary outcomes across the 2 conditions using hierarchical linear modeling (HLM). We will compute the change trajectories on each outcome over the course of the study assessments (ie, at baseline, immediately postintervention, and at 3-, 6-, and 12-month follow-ups). These trajectories will then be averaged together within each condition, so we can compare the trajectories for each outcome across the 2 conditions to determine if there was greater improvement in the positive emotion regulation skills intervention group relative to the control group.

We plan to use participants' daily assessments in 2 ways. First, we will compute growth trajectories for each participant using their daily assessments to explore when people tend to experience improvements in diabetes-related distress, diabetes regimen adherence, and mood during the intervention. Second, as retrospective reports can sometimes lead to inflated or inaccurate information compared with daily assessments [75], we will use daily assessments to compute weekly averages for diabetes-related distress, diabetes regimen adherence, and mood during and after the intervention. These weekly averages will then be used as outcome variables in the same HLM analyses described earlier.

\section{2,222 \\ Joined}

Previous research on the impact of health care interventions on people with poorly managed diabetes suggests that effects may be most effective among people with especially poor glycemic control or $\mathrm{HbA}_{1 \mathrm{c}}$ levels above $9.5 \%$ [76]. Consequently, we plan to examine the effects of baseline $\mathrm{HbA}_{1 \mathrm{c}}$ as a moderator of the effects of the intervention on changes in the primary and secondary outcomes. Similarly, we also plan to examine the effects of baseline depressive symptoms as a moderator of the effects of the intervention. Finally, given that the effects of Happify Health use are typically moderated by usage [57-61], we plan to examine the effects of frequency of usage as another moderator of changes in the primary and secondary outcomes.

\section{Ethics}

This study was submitted and approved for ethical review by IntegReview (protocol HLS-07), an independent institutional review board.

\section{Results}

Recruitment for the trial is expected to begin during the second quarter of 2020, and participants will begin the 8-week intervention as they are recruited and consent to participate in the study. Consequently, the first wave of data collection is expected to be complete approximately 8 weeks after 
recruitment, with an estimated intervention completion date for all participants in the fourth quarter. We plan to conduct data analysis for postintervention assessments once this initial data collection is complete, and these results may be shared at conferences or submitted for publication while we continue to collect data for the 3-, 6-, and 12-month follow-up assessments. Owing to the high cost associated with this research, we plan to conduct preliminary analyses once $20 \%$ of our target sample has completed the 8 -week intervention. If we find no trends suggesting Happify Health use predicts primary outcomes, we plan to discontinue the study.

Recruitment, data monitoring for participant safety, data storage, protocol implementation, and research administration (participant follow-up, etc) will be under the purview of EB, GK, JS, and AP as employees of Happify Health. All data analyses will be conducted by JM and IK.

\section{Discussion}

Previous research suggests that many of the costs associated with diabetes are preventable when individuals with a diabetes diagnosis manage their condition more effectively $[9,10,12]$. One factor that appears to interfere with individuals' ability to manage their diabetes is depression [18], which is more common among people with a diabetes diagnosis than in the general population [15]. Interventions targeting depression among people with diabetes show promise in helping to improve psychological as well as physical health outcomes [30,31]. Research testing these interventions, however, focuses primarily on in-person interventions and has yielded mixed results, particularly on diabetes-specific outcomes. The purpose of the outlined study is to examine the effectiveness of a digital therapeutics platform (Happify Health) shown to improve mental health over the course of 8 weeks among general populations [59], distressed populations [62], and people living with chronic physical conditions [64], specifically in a population of adults with poorly controlled type 2 diabetes and elevated depressive symptoms.

\section{Strengths and Limitations}

Previous research demonstrated that 8 weeks of Happify Health use improved subjective well-being among people with chronic physical conditions, including type 2 diabetes, at the same rate as people without these conditions [61]. However, the previous study examined the effects of Happify Health use on users with at least one self-reported chronic condition but was unable to examine the impact on users with specific chronic conditions. Therefore, this will be the first attempt to examine the effects of Happify Health use specifically on individuals with type 2 diabetes. Moreover, the previous study assessed only well-being, whereas this study will examine depressive symptoms and, more importantly, diabetes-specific outcomes such as $\mathrm{HbA}_{1 \mathrm{c}}$, frequency of self-care behaviors, and diabetes-related distress. Consequently, this study will provide a more comprehensive analysis of whether Happify Health use can improve physical health outcomes as well as psychological outcomes among individuals with poorly managed type 2 diabetes and elevated depressive symptoms.
This study also plans to include 3-, 6-, and 12-month follow-up assessments, providing important information about the longitudinal effects of this intervention. Longitudinal research on the impact of psychological interventions on people with diabetes remains limited [30], but research suggests that long-term follow-ups are important, as some effects may dissipate over time [30], whereas other effects may only emerge or become stronger over time [30,31].

Previous research has also been characterized by small samples, with sample sizes for in-person interventions ranging from 23 to 139 [30]. Sample sizes for research testing digital interventions have often been higher; however, most of these studies assessed only psychological well-being (depression and diabetes-related distress) and not physical health outcomes such as glycemic control [47]. Although the levels of attrition for long-term follow-up assessments are difficult to predict, based on response rates in previous RCT research using Happify Health ranging from $56 \%$ to $72 \%$ for 8 -week interventions [60], our sample size postintervention is likely to be substantially higher than that in the previous studies. Given the mixed findings with glycemic control in previous research, it is important to examine these effects with larger samples to determine whether previous null findings are related to a lack of power.

However, one limitation of this study is that we are targeting a specific group of people with poorly managed diabetes and elevated depressive symptoms. Furthermore, because participants will have to successfully complete a run-in period before starting the study, our participants are also likely to differ from those who do not participate in terms of motivation, conscientiousness, etc. Thus, it is unclear whether our findings will generalize to a broader population of individuals with type 2 diabetes.

Another limitation of this study is that the intervention does not specifically focus on diabetes-related content. That is, participants in the positive emotion regulation skills intervention group may choose to complete the featured track, which includes a description cueing them to think about the impact of negative emotions on their diabetes, but activities within this featured track do not refer specifically to diabetes or incorporate diabetes-specific behavioral strategies. Furthermore, participants are not required to complete, or even begin, this track and may choose from any other available tracks that do not refer to diabetes whatsoever. Consequently, our intervention is similar to mindfulness or PP interventions that are broader in focus [30]. By comparison, CBT applied to people with diabetes typically has been modified to include specific information about adherence [34] or include supportive diabetes information [35]. Thus, our intervention may have weaker effects, particularly on diabetes-specific outcomes, than CBT modified for diabetes. However, there is preliminary evidence that completing regular activities (ie, not disease specific) on Happify Health is associated with improved subjective well-being among people with chronic physical conditions [61] and that mindfulness and PP interventions without behavioral strategies for managing diabetes can improve participants' health outcomes [30]. If we are able to demonstrate that Happify Health use can have physical as well as psychological benefits for people with 
poorly managed type 2 diabetes and elevated depressive symptoms, without incorporating specific behavioral strategies for managing diabetes, the effects are also likely to have broader applicability.

\section{Conclusions}

Given the buffering effects of psychological well-being on diabetes outcomes [23], researchers and practitioners have become increasingly interested in whether psychological interventions can improve diabetes-related outcomes among people living with diabetes [30]. This trial would add to the emerging literature testing the effectiveness of such interventions. Importantly, however, although most previous research focused on interventions delivered in person [30], this study tests the efficacy of a digital intervention, which has the added benefit of reducing many of the barriers that prevent people from seeking treatment [77]. This study also addresses two important limitations of previous research: (1) small sample sizes and (2) lack of long-term follow-ups [30]. Consequently, this trial will not only provide information about the immediate effects of a digital therapeutic intervention on diabetes-related outcomes but also the extent to which these effects may persist for up to 12 months.

\section{Acknowledgments}

The authors would like to thank Allison L Williams for her assistance in planning this study.

\section{Authors' Contributions}

EB contributed to designing the study and wrote the initial draft of this protocol. JM and AP contributed substantially to the study aims, scope, and design of the study. GK contributed substantially to the design of the study. JS contributed to designing the study and provided general manuscript support for this protocol. IK contributed to the study design.

\section{Conflicts of Interest}

EB, GK, JS, and AP are employees of Happify Health.

\section{References}

1. Whiting DR, Guariguata L, Weil C, Shaw J. IDF diabetes atlas: global estimates of the prevalence of diabetes for 2011 and 2030. Diabetes Res Clin Pract 2011 Dec;94(3):311-321. [doi: 10.1016/j.diabres.2011.10.029] [Medline: 22079683]

2. GBD 2015 Mortality and Causes of Death Collaborators. Global, regional, and national life expectancy, all-cause mortality, and cause-specific mortality for 249 causes of death, 1980-2015: a systematic analysis for the global burden of disease study 2015. Lancet 2016 Oct 8;388(10053):1459-1544 [FREE Full text] [doi: 10.1016/S0140-6736(16)31012-1] [Medline: 27733281]

3. Menke A, Casagrande S, Geiss L, Cowie CC. Prevalence of and trends in diabetes among adults in the United States, 1988-2012. J Am Med Assoc 2015 Sep 8;314(10):1021-1029. [doi: 10.1001/jama.2015.10029] [Medline: 26348752]

4. Centers for Disease Control and Prevention. 2020. National Diabetes Statistics Report 2020: Estimates of Diabetes and Its Burden in the United States URL: https://www.cdc.gov/diabetes/pdfs/data/statistics/national-diabetes-statistics-report.pdf [accessed 2020-01-27]

5. Wild S, Roglic G, Green A, Sicree R, King H. Global prevalence of diabetes: estimates for the year 2000 and projections for 2030. Diabetes Care 2004 May;27(5):1047-1053. [doi: 10.2337/diacare.27.5.1047] [Medline: $\underline{15111519]}$

6. Riddle MC, Herman WH. The cost of diabetes care-an elephant in the room. Diabetes Care 2018 May;41(5):929-932. [doi: 10.2337/dci18-0012] [Medline: 29678864]

7. American Diabetes Association. Economic costs of diabetes in the US in 2017. Diabetes Care 2018 May;41(5):917-928 [FREE Full text] [doi: 10.2337/dci18-0007] [Medline: 29567642]

8. Bommer C, Sagalova V, Heesemann E, Manne-Goehler J, Atun R, Bärnighausen T, et al. Global economic burden of diabetes in adults: projections from 2015 to 2030. Diabetes Care 2018 May;41(5):963-970. [doi: 10.2337/dc17-1962] [Medline: 29475843]

9. Rubens M, Saxena A, Ramamoorthy V, Khera R, Hong J, Veledar E, et al. Trends in diabetes-related preventable hospitalizations in the US, 2005-2014. Diabetes Care 2018 May;41(5):e72-e73. [doi: 10.2337/dc17-1942] [Medline: 29378777]

10. Shrestha SS, Zhang P, Hora I, Geiss LS, Luman ET, Gregg EW. Factors contributing to increases in diabetes-related preventable hospitalization costs among US adults during 2001-2014. Diabetes Care 2019 Jan;42(1):77-84. [doi: 10.2337/dc18-1078] [Medline: 30455326]

11. Cramer JA. A systematic review of adherence with medications for diabetes. Diabetes Care 2004 May;27(5):1218-1224. [doi: 10.2337/diacare.27.5.1218] [Medline: 15111553 ]

12. Ho PM, Rumsfeld JS, Masoudi FA, McClure DL, Plomondon ME, Steiner JF, et al. Effect of medication nonadherence on hospitalization and mortality among patients with diabetes mellitus. Arch Intern Med 2006 Sep 25;166(17):1836-1841. [doi: 10.1001/archinte.166.17.1836] [Medline: 17000939]

13. Vincze G, Barner JC, Lopez D. Factors associated with adherence to self-monitoring of blood glucose among persons with diabetes. Diabetes Educ 2004;30(1):112-125. [doi: 10.1177/014572170403000119] [Medline: 14999899] 
14. Jerant AF, von Friederichs-Fitzwater MM, Moore M. Patients' perceived barriers to active self-management of chronic conditions. Patient Educ Couns 2005 Jun;57(3):300-307. [doi: 10.1016/j.pec.2004.08.004] [Medline: 15893212]

15. Ali S, Stone MA, Peters JL, Davies MJ, Khunti K. The prevalence of co-morbid depression in adults with type 2 diabetes: a systematic review and meta-analysis. Diabet Med 2006 Nov;23(11):1165-1173. [doi: 10.1111/j.1464-5491.2006.01943.x] [Medline: 17054590$]$

16. Strandberg RB, Graue M, Wentzel-Larsen T, Peyrot M, Rokne B. Relationships of diabetes-specific emotional distress, depression, anxiety, and overall well-being with HbA1c in adult persons with type 1 diabetes. J Psychosom Res 2014 Sep;77(3):174-179 [FREE Full text] [doi: 10.1016/j.jpsychores.2014.06.015] [Medline: 25149027]

17. Leyva B, Zagarins SE, Allen NA, Welch G. The relative impact of diabetes distress vs depression on glycemic control in hispanic patients following a diabetes self-management education intervention. Ethn Dis 2011;21(3):322-327. [Medline: 21942165]

18. Ciechanowski PS, Katon WJ, Russo JE. Depression and diabetes: impact of depressive symptoms on adherence, function, and costs. Arch Intern Med 2000 Nov 27;160(21):3278-3285. [doi: 10.1001/archinte.160.21.3278] [Medline: 11088090]

19. Mai Q, Holman CD, Sanfilippo FM, Emery JD. The impact of mental illness on potentially preventable hospitalisations: a population-based cohort study. BMC Psychiatry 2011 Oct 10;11:163 [FREE Full text] [doi: 10.1186/1471-244X-11-163] [Medline: 21985082]

20. Lloyd CE, Pambianco G, Orchard T. Does diabetes-related distress explain the presence of depressive symptoms and/or poor self-care in individuals with type 1 diabetes? Diabet Med 2010 Feb;27(2):234-237 [FREE Full text] [doi: 10.1111/j.1464-5491.2009.02896.x] [Medline: 20546270]

21. Moskowitz JT, Epel ES, Acree M. Positive affect uniquely predicts lower risk of mortality in people with diabetes. Health Psychol 2008 Jan;27(1S):S73-S82. [doi: 10.1037/0278-6133.27.1.S73] [Medline: 18248108]

22. Cohn MA, Pietrucha ME, Saslow LR, Hult JR, Moskowitz JT. An online positive affect skills intervention reduces depression in adults with type 2 diabetes. J Posit Psychol 2014 Jan 1;9(6):523-534 [FREE Full text] [doi: 10.1080/17439760.2014.920410] [Medline: 25214877]

23. Robertson SM, Stanley MA, Cully JA, Naik AD. Positive emotional health and diabetes care: concepts, measurement, and clinical implications. Psychosomatics 2012;53(1):1-12. [doi: 10.1016/j.psym.2011.09.008] [Medline: 22221716]

24. Strine TW, Chapman DP, Balluz LS, Moriarty DG, Mokdad AH. The associations between life satisfaction and health-related quality of life, chronic illness, and health behaviors among US community-dwelling adults. J Community Health 2008 Feb;33(1):40-50. [doi: 10.1007/s10900-007-9066-4] [Medline: 18080207]

25. Grant N, Wardle J, Steptoe A. The relationship between life satisfaction and health behavior: a cross-cultural analysis of young adults. Int J Behav Med 2009;16(3):259-268. [doi: 10.1007/s12529-009-9032-x] [Medline: 19319695]

26. Ferrari M, Dal Cin M, Steele M. Self-compassion is associated with optimum self-care behaviour, medical outcomes and psychological well-being in a cross-sectional sample of adults with diabetes. Diabet Med 2017 Nov;34(11):1546-1553. [doi: 10.1111/dme.13451] [Medline: 28799282]

27. Neff KD. The development and validation of a scale to measure self-compassion. Self Identity 2003 Jul;2(3):223-250. [doi: 10.1080/15298860309027]

28. Piette JD, Richardson C, Valenstein M. Addressing the needs of patients with multiple chronic illnesses: the case of diabetes and depression. Am J Manag Care 2004 Feb;10(2 Pt 2):152-162 [FREE Full text] [Medline: 15005508 ]

29. Bolier L, Haverman M, Westerhof GJ, Riper H, Smit F, Bohlmeijer E. Positive psychology interventions: a meta-analysis of randomized controlled studies. BMC Public Health 2013 Feb 8;13:119 [FREE Full text] [doi: 10.1186/1471-2458-13-119] [Medline: 23390882]

30. Massey CN, Feig EH, Duque-Serrano L, Wexler D, Moskowitz JT, Huffman JC. Well-being interventions for individuals with diabetes: a systematic review. Diabetes Res Clin Pract 2019 Jan;147:118-133 [FREE Full text] [doi: 10.1016/j.diabres.2018.11.014] [Medline: $\underline{\text { 30500545] }}$

31. Bogusch LM, O'Brien WH. The effects of mindfulness-based interventions on diabetes-related distress, quality of life, and metabolic control among persons with diabetes: a meta-analytic review. Behav Med 2019;45(1):19-29. [doi: 10.1080/08964289.2018.1432549] [Medline: 29617221]

32. Guo J, Wang H, Luo J, Guo Y, Xie Y, Lei B, et al. Factors influencing the effect of mindfulness-based interventions on diabetes distress: a meta-analysis. BMJ Open Diabetes Res Care 2019;7(1):e000757 [FREE Full text] [doi: 10.1136/bmjdrc-2019-000757] [Medline: 31908794]

33. Snoek FJ, van der Ven NC, Twisk JW, Hogenelst MH, Tromp-Wever AM, van der Ploeg HM, et al. Cognitive behavioural therapy (CBT) compared with blood glucose awareness training (BGAT) in poorly controlled Type 1 diabetic patients: long-term effects on HbA moderated by depression. A randomized controlled trial. Diabet Med 2008 Nov;25(11):1337-1342. [doi: 10.1111/j.1464-5491.2008.02595.x] [Medline: 19046225]

34. Safren SA, Gonzalez JS, Wexler DJ, Psaros C, Delahanty LM, Blashill AJ, et al. A randomized controlled trial of cognitive behavioral therapy for adherence and depression (CBT-AD) in patients with uncontrolled type 2 diabetes. Diabetes Care 2014;37(3):625-633 [FREE Full text] [doi: 10.2337/dc13-0816] [Medline: 24170758] 
35. Lustman PJ, Griffith LS, Freedland KE, Kissel SS, Clouse RE. Cognitive behavior therapy for depression in type 2 diabetes mellitus. A randomized, controlled trial. Ann Intern Med 1998 Oct 15;129(8):613-621. [doi: 10.7326/0003-4819-129-8-199810150-00005] [Medline: 9786808]

36. Li C, Xu D, Hu M, Tan Y, Zhang P, Li G, et al. A systematic review and meta-analysis of randomized controlled trials of cognitive behavior therapy for patients with diabetes and depression. J Psychosom Res 2017 Apr;95:44-54. [doi: 10.1016/j.jpsychores.2017.02.006] [Medline: 28314548]

37. Mojtabai R, Olfson M, Sampson NA, Jin R, Druss B, Wang PS, et al. Barriers to mental health treatment: results from the national comorbidity survey replication. Psychol Med 2011 Aug;41(8):1751-1761 [FREE Full text] [doi: 10.1017/S0033291710002291] [Medline: 21134315]

38. Conner KO, Copeland VC, Grote NK, Koeske G, Rosen D, Reynolds CF, et al. Mental health treatment seeking among older adults with depression: the impact of stigma and race. Am J Geriatr Psychiatry 2010 Jun;18(6):531-543 [FREE Full text] [doi: 10.1097/JGP.0b013e3181cc0366] [Medline: 20220602]

39. Thomas KC, Ellis AR, Konrad TR, Holzer CE, Morrissey JP. County-level estimates of mental health professional shortage in the United States. Psychiatr Serv 2009 Oct;60(10):1323-1328. [doi: 10.1176/ps.2009.60.10.1323] [Medline: 19797371]

40. Warmerdam L, Smit F, van Straten A, Riper H, Cuijpers P. Cost-utility and cost-effectiveness of internet-based treatment for adults with depressive symptoms: randomized trial. J Med Internet Res 2010 Dec 19;12(5):e53 [FREE Full text] [doi: 10.2196/jmir.1436] [Medline: 21169166]

41. Ferwerda M, van Beugen S, van Burik A, van Middendorp H, de Jong EM, van de Kerkhof PC, et al. What patients think about e-health: patients' perspective on internet-based cognitive behavioral treatment for patients with rheumatoid arthritis and psoriasis. Clin Rheumatol 2013 Jun;32(6):869-873. [doi: 10.1007/s10067-013-2175-9] [Medline: 23354514]

42. Gerhards SA, Abma TA, Arntz A, de Graaf LE, Evers SM, Huibers MJ, et al. Improving adherence and effectiveness of computerised cognitive behavioural therapy without support for depression: a qualitative study on patient experiences. $\mathrm{J}$ Affect Disord 2011 Mar;129(1-3):117-125. [doi: 10.1016/j.jad.2010.09.012] [Medline: 20889214]

43. van Bastelaar K, Cuijpers P, Pouwer F, Riper H, Snoek FJ. Development and reach of a web-based cognitive behavioural therapy programme to reduce symptoms of depression and diabetes-specific distress. Patient Educ Couns 2011 Jul;84(1):49-55. [doi: 10.1016/j.pec.2010.06.013] [Medline: 20619577]

44. Beratarrechea A, Lee AG, Willner JM, Jahangir E, Ciapponi A, Rubinstein A. The impact of mobile health interventions on chronic disease outcomes in developing countries: a systematic review. Telemed J E Health 2014 Jan;20(1):75-82 [FREE Full text] [doi: 10.1089/tmj.2012.0328] [Medline: 24205809]

45. Andersson G, Titov N. Advantages and limitations of internet-based interventions for common mental disorders. World Psychiatry 2014 Feb;13(1):4-11 [FREE Full text] [doi: 10.1002/wps.20083] [Medline: 24497236]

46. Wang Y, Xue H, Huang Y, Huang L, Zhang D. A systematic review of application and effectiveness of mhealth interventions for obesity and diabetes treatment and self-management. Adv Nutr 2017 May;8(3):449-462 [FREE Full text] [doi: 10.3945/an.116.014100] [Medline: 28507010]

47. Hadjiconstantinou M, Byrne J, Bodicoat DH, Robertson N, Eborall H, Khunti K, et al. Do web-based interventions improve well-being in type 2 diabetes? A systematic review and meta-analysis. J Med Internet Res 2016 Oct 21;18(10):e270 [FREE Full text] [doi: 10.2196/jmir.5991] [Medline: 27769955]

48. Quinn CC, Swasey KK, Crabbe JC, Shardell MD, Terrin ML, Barr EA, et al. The impact of a mobile diabetes health intervention on diabetes distress and depression among adults: secondary analysis of a cluster randomized controlled trial. JMIR Mhealth Uhealth 2017 Dec 7;5(12):e183 [FREE Full text] [doi: 10.2196/mhealth.8910] [Medline: 29217502]

49. van Bastelaar KM, Pouwer F, Cuijpers P, Riper H, Snoek FJ. Web-based depression treatment for type 1 and type 2 diabetic patients: a randomized, controlled trial. Diabetes Care 2011 Feb;34(2):320-325 [FREE Full text] [doi: 10.2337/dc10-1248] [Medline: 21216855]

50. Beck AT, Rush AJ, Shaw BF, Emery G. Cognitive Therapy of Depression. New York, USA: Guilford Press; 1979.

51. Praissman S. Mindfulness-based stress reduction: a literature review and clinician's guide. J Am Acad Nurse Pract 2008 Apr;20(4):212-216. [doi: 10.1111/j.1745-7599.2008.00306.x] [Medline: 18387018]

52. Sin NL, Lyubomirsky S. Enhancing well-being and alleviating depressive symptoms with positive psychology interventions: a practice-friendly meta-analysis. J Clin Psychol 2009 May;65(5):467-487. [doi: 10.1002/jclp.20593] [Medline: 19301241]

53. Schueller SM, Parks AC. Disseminating self-help: positive psychology exercises in an online trial. J Med Internet Res 2012 Jun 25;14(3):e63 [FREE Full text] [doi: 10.2196/jmir.1850] [Medline: 22732765]

54. Seligman ME, Steen TA, Park N, Peterson C. Positive psychology progress: empirical validation of interventions. Am Psychol 2005;60(5):410-421. [doi: 10.1037/0003-066X.60.5.410] [Medline: 16045394]

55. Chambless DL, Hollon SD. Defining empirically supported therapies. J Consult Clin Psychol 1998 Feb;66(1):7-18. [doi: 10.1037//0022-006x.66.1.7] [Medline: 9489259]

56. Sheldon KM, Elliot AJ. Goal striving, need satisfaction, and longitudinal well-being: the self-concordance model. J Pers Soc Psychol 1999 Mar;76(3):482-497. [doi: 10.1037//0022-3514.76.3.482] [Medline: 10101878]

57. Carpenter J, Crutchley P, Zilca RD, Schwartz HA, Smith LK, Cobb AM, et al. Seeing the 'big' picture: big data methods for exploring relationships between usage, language, and outcome in internet intervention data. J Med Internet Res 2016 Aug 31;18(8):e241 [FREE Full text] [doi: 10.2196/jmir.5725] [Medline: 27580524] 
58. Carpenter J, Crutchley P, Zilca RD, Schwartz HA, Smith LK, Cobb AM, et al. Correction: seeing the 'big' picture: big data methods for exploring relationships between usage, language, and outcome in internet intervention data. J Med Internet Res 2017 Dec 19;19(12):e347 [FREE Full text] [doi: 10.2196/jmir.8099] [Medline: 29258059]

59. Parks AC, Williams AL, Tugade MM, Hokes KE, Honomichl RD, Zilca RD. Testing a scalable web and smartphone based intervention to improve depression, anxiety, and resilience: a randomized controlled trial. Int J Wellbeing 2018 Dec 8;8(2):22-67. [doi: 10.5502/ijw.v8i2.745]

60. Williams AL, Parks AC, Cormier G, Stafford J, Whillans A. Improving resilience among employees high in depression, anxiety, and workplace distress. Int J Manag Res 2018;9(1-2):4-22 [FREE Full text]

61. Parks AC, Williams AL, Kackloudis GM, Stafford JL, Boucher EM, Honomichl RD. The effects of a digital well-being intervention on patients with chronic conditions: observational study. J Med Internet Res 2020 Jan 10;22(1):e16211 [FREE Full text] [doi: 10.2196/16211] [Medline: 31922491]

62. Kroenke K, Spitzer RL. The PHQ-9: a new depression diagnostic and severity measure. Psychiatric Annals 2002 Sep 1;32(9):509-515. [doi: 10.3928/0048-5713-20020901-06]

63. American Diabetes Association. Glycemic targets: standards of medical care in diabetes-2019. Diabetes Care 2019 Jan;42(Suppl 1):S61-S70. [doi: 10.2337/dc19-S006] [Medline: 30559232]

64. van Son J, Nyklíček I, Pop VJ, Blonk MC, Erdtsieck RJ, Pouwer F. Mindfulness-based cognitive therapy for people with diabetes and emotional problems: long-term follow-up findings from the DiaMind randomized controlled trial. J Psychosom Res 2014 Jul;77(1):81-84 [FREE Full text] [doi: 10.1016/j.jpsychores.2014.03.013] [Medline: 24913347]

65. Kopf S, Oikonomou D, Hartmann M, Feier F, Faude-Lang V, Morcos M, et al. Effects of stress reduction on cardiovascular risk factors in type 2 diabetes patients with early kidney disease - results of a randomized controlled trial (HEIDIS). Exp Clin Endocrinol Diabetes 2014 Jun;122(6):341-349. [doi: 10.1055/s-0034-1372583] [Medline: 24798861]

66. Eysenbach G. The law of attrition. J Med Internet Res 2005 Mar 31;7(1):e11 [FREE Full text] [doi: 10.2196/jmir.7.1.e11] [Medline: 15829473]

67. Christensen H, Griffiths KM, Farrer L. Adherence in internet interventions for anxiety and depression. J Med Internet Res 2009 Apr 24;11(2):e13 [FREE Full text] [doi: 10.2196/jmir.1194] [Medline: 19403466]

68. Polonsky WH, Fisher L, Earles J, Dudl RJ, Lees J, Mullan J, et al. Assessing psychosocial distress in diabetes: development of the diabetes distress scale. Diabetes Care 2005 Mar;28(3):626-631. [doi: 10.2337/diacare.28.3.626] [Medline: 15735199]

69. Morisky DE, Green LW, Levine DM. Concurrent and predictive validity of a self-reported measure of medication adherence. Med Care 1986 Jan;24(1):67-74. [doi: 10.1097/00005650-198601000-00007] [Medline: 3945130]

70. Toobert DJ, Hampson SE, Glasgow RE. The summary of diabetes self-care activities measure: results from 7 studies and a revised scale. Diabetes Care 2000 Jul;23(7):943-950 [FREE Full text] [doi: 10.2337/diacare.23.7.943] [Medline: 10895844]

71. Cella D, Yount S, Rothrock N, Gershon R, Cook K, Reeve B, PROMIS Cooperative Group. The patient-reported outcomes measurement information system (PROMIS): progress of an NIH roadmap cooperative group during its first two years.

Med Care 2007 May;45(5 Suppl 1):S3-11 [FREE Full text] [doi: 10.1097/01.mlr.0000258615.42478.55] [Medline: 17443116]

72. Starr LR, Davila J. Temporal patterns of anxious and depressed mood in generalized anxiety disorder: a daily diary study. Behav Res Ther 2012 Feb;50(2):131-141 [FREE Full text] [doi: 10.1016/j.brat.2011.11.005] [Medline: 22196213]

73. Diener E, Seligman ME. Very happy people. Psychol Sci 2002 Jan;13(1):81-84. [doi: 10.1111/1467-9280.00415] [Medline: $\underline{11894851]}$

74. Mehl MR, Vazire S, Holleran SE, Clark CS. Eavesdropping on happiness: well-being is related to having less small talk and more substantive conversations. Psychol Sci 2010 Apr;21(4):539-541 [FREE Full text] [doi: 10.1177/0956797610362675] [Medline: 20424097]

75. Lewandowski AS, Palermo TM, Kirchner HL, Drotar D. Comparing diary and retrospective reports of pain and activity restriction in children and adolescents with chronic pain conditions. Clin J Pain 2009 May;25(4):299-306 [FREE Full text] [doi: 10.1097/AJP.0b013e3181965578] [Medline: 19590478]

76. Murphy ME, Byrne M, Galvin R, Boland F, Fahey T, Smith SM. Improving risk factor management for patients with poorly controlled type 2 diabetes: a systematic review of healthcare interventions in primary care and community settings. BMJ Open 2017 Aug 4;7(8):e015135 [FREE Full text] [doi: 10.1136/bmjopen-2016-015135] [Medline: 28780542]

77. Kazdin AE. Clinical psychological science editorial. Clin Psychol Sci 2013 Nov 15;2(1):3-5. [doi: $10.1177 / 2167702613514513]$

\section{Abbreviations}

CBT: cognitive behavioral therapy

$\mathbf{H b A}_{1 \mathbf{c}}$ : hemoglobin $\mathrm{A}_{1 \mathrm{c}}$

HLM: hierarchical linear modeling

MBSR: mindfulness-based stress reduction

PHQ: Patient Health Questionnaire

PP: positive psychology

RCT: randomized controlled trial 


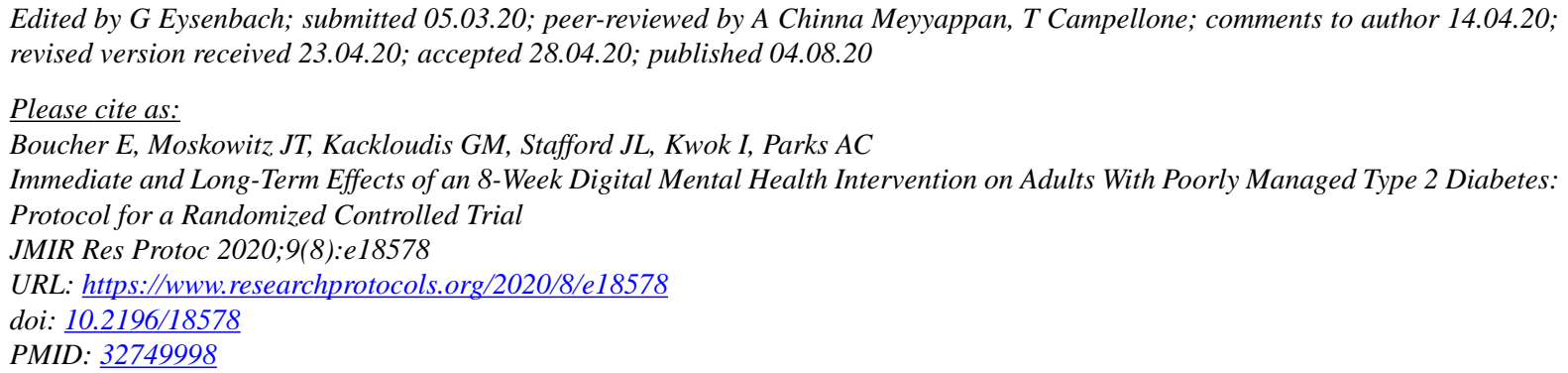

CEliane Boucher, Judith T Moskowitz, Gina M Kackloudis, Julia L Stafford, Ian Kwok, Acacia C Parks. Originally published in JMIR Research Protocols (http://www.researchprotocols.org), 04.08.2020. This is an open-access article distributed under the terms of the Creative Commons Attribution License (https://creativecommons.org/licenses/by/4.0/), which permits unrestricted use, distribution, and reproduction in any medium, provided the original work, first published in JMIR Research Protocols, is properly cited. The complete bibliographic information, a link to the original publication on http://www.researchprotocols.org, as well as this copyright and license information must be included. 